\title{
Prevalence and determinants of biochemical dysfunction of the liver in Atayal Aboriginal community of Taiwan: Is betel nut chewing a risk factor?
}

\author{
Ching-Feng Lin ${ }^{1,2,5}$, Tun-Jen Shiau ${ }^{1}$, Ying-Chin $\mathrm{Ko}^{3,4}$, Ping-Ho Chen ${ }^{4}$ and \\ Jung-Der Wang*1
}

\begin{abstract}
Address: ${ }^{1}$ Institute of Occupational Medicine and Industrial Hygiene, National Taiwan University, College of Public Health and Department of Internal Medicine, National Taiwan University Hospital, Taipei, Taiwan, ${ }^{2}$ Department of Health, Executive Yuan, Taiwan, ${ }^{3}$ Department of Public Health, Faculty of Medicine, College of Medicine, Kaohsiung Medical University, Kaohsiung, Taiwan, ${ }^{4}$ Division of Environmental Health and Occupational Medicine, National Health Research Institutes, Taiwan and ${ }^{5}$ School of Public Health, Taipei Medical University, Taiwan
\end{abstract}

Email: Ching-Feng Lin - baliowl@mail.bali.doh.gov.tw; Tun-Jen Shiau - adlcf@doh.gov.tw; Ying-Chin Ko - ycko@nhri.org.tw; PingHo Chen - phchen@nhri.org.tw; Jung-Der Wang* - jdwang@ntu.edu.tw

* Corresponding author

Published: 27 April 2008

BMC Gastroenterology 2008, 8:13 doi:10.1186/1471-230X-8-13

This article is available from: http://www.biomedcentral.com/I47I-230X/8/I3

(c) 2008 Lin et al; licensee BioMed Central Ltd.

This is an Open Access article distributed under the terms of the Creative Commons Attribution License (http://creativecommons.org/licenses/by/2.0), which permits unrestricted use, distribution, and reproduction in any medium, provided the original work is properly cited.

\begin{abstract}
Background: We address the independent and interactive roles of habitual betel quid chewing and other known risk factors for biochemical dysfunction and cirrhosis of the liver.

Methods: To determine the prevalence rates and risk factors associated with biochemical dysfunction of the liver, a total of 3,010 adult residents in an Atayal Aboriginal community were invited to participate in the study. Abdominal ultrasonography was used to diagnose liver cirrhosis.

Results: There were 2,063 Atayal Aboriginal and 947 non-Aboriginal in this study. The result showed overall prevalence rates for hepatitis $B$ surface antigen $(\mathrm{HBsAg})$ and hepatitis $C$ virus $(\mathrm{HCV})$ were $21.2 \%$ and $2.9 \%$, respectively. There were $16.5 \%, 15.1 \%$ and $22.4 \%$ subjects with abnormal alanine aminotransferase (ALT), aspartate aminotransferase (AST), and gamma glutamyl transpeptidase (GGT), accordingly. Multiple logistic regression analysis showed that combined infections with $\mathrm{HBV}$ and $\mathrm{HCV}$ presented with the highest risks with $\mathrm{OR}$ (odds ratio) and $95 \% \mathrm{Cl}$ (confidence interval) of $4.2(1.2-17.4)$ and $3.8(1.0-14.1)$, respectively for elevation of ALT and AST; followed by alcohol (I.7 and 3.I), male gender (I.7 and I.6), betel quid (I.5 and I.3), smoking (I.4 and I.8), and aboriginal (I.4 and I.3). There is effect-measure modification between viral infection and betel quid chewing for increased severity of abnormal ALT elevation. Among I,382 subjects consenting to abdominal ultrasonography, $4 \mathrm{I}(3.0 \%)$ were found to have liver cirrhosis with the same factors associated with higher risks.
\end{abstract}

Conclusion: In addition to infections with viral hepatitis B and/or C, we found Atayal Aboriginal, males, current smokers, drinkers and betel quid chewers were independently associated with biochemical dysfunction and probably cirrhosis of the liver. Further study is needed to corroborate the above hypothesis. 


\section{Background}

Health inequity and disparities have been demonstrated to exist between Aboriginal and non-Aboriginal in the USA, Australia, Taiwan and other countries [1]. In Australia, for almost all disease categories, rates for Aboriginal were higher than those for other Australians, which were mainly attributed to the hypothesis of social and economic inequality [2-4]. Such an inequality may result in an increase of not only infectious diseases but also almost every kind of diseases associated with diet, exercise patterns, apathy and health behavior, such as alcohol drinking, cigarette smoking, betel quid chewing and obesity [1].

The population of Taiwan is 23 million, consisting of Hokkien (73\%), Hakka (12\%), Mainland Chinese (13\%), and Aboriginal (2\%) ethnic groups [5]. There are twelve Aboriginal tribes in Taiwan and constitute approximately 460,000 Aboriginal of the Taiwanese (general) population. Although there have been long term mixed marriage with other ethnic groups, Taiwan Aboriginal still preserved their own languages, customs and social organizations. In hereditary characteristics, they are markedly different from the rest of Taiwanese population [6]. Their health status, as evaluated by life expectancy, mortality rates and the prevalence and incidence of various diseases such as accident, liver disease and other diseases, was worse than that of the general population in Taiwan [1]. A more recent investigation indicated that the discrepancy of life expectancy between Aboriginal and non-Aboriginal were slightly reduced, but the life expectancy of Aboriginal were on average 10 years less than that of the general population, with a standardized mortality ratio approaching 2-fold [7].

Taiwan is known for the high prevalence of chronic hepatitis B virus (HBV) infection, with a positive rate of 15-20 $\%$ for hepatitis B surface antigen (HBsAg) [8,9], which was also reported among Aboriginal people [8]. The prevalence of hepatitis $\mathrm{C}$ infection was around 2-4\% [10]. Aboriginal in Taiwan were also found to have a high prevalence rate of alcoholism, estimated at about 20-30\% $[11,12]$, which may result in abnormal liver function or even chronic liver injury. Thus, abnormal liver function in Aboriginal people in Taiwan has usually been considered to be virus or alcohol related.

Betel quid chewing is a prevalent habit in $10-20 \%$ of the general population [13], and is also part of traditional Aboriginal culture usually taken with alcohol during festival or traditional ceremony in Taiwan [14]. The betel quid prepared in Atayal aboriginal community of Taiwan is quite different from those in other parts of the world. It usually consists of 2 halves of a fresh areca nut (fruit of the Areca catechu Linn.), sandwiched with a piece of the betel leaf, and white slaked lime paste, instead of the reddish inflorescence. Betel quid chewers generally swallow the saliva completely, thus bathing the epithelial lining of the upper digestive tract with the toxins released during chewing. Such a practice may increase the possibility of toxic effects of betel quid at target organs other than the oral cavity [15]. In 2004, the International Agency for Research on Cancer (IARC) declared chewing of betel quid, by itself, to be a Group 1 carcinogen and the areca nut to be, correspondingly, a Group 1 carcinogen [16]. Chewing betel quid independently contributes to the risk of oropharyngeal cancer [17-19], oral mucosal lesions [20], oral leukoplakia [21], oral submucous fibrosis (OSF) [21], liver cirrhosis [22,23], hepatocellular carcinoma (HCC) [24], diabetes mellitus [25] and adverse outcomes with use during pregnancy [26]. Endogenous formation of areca-nut-derived nitrosamines was found in vivo or in vitro studies, suggesting that the damage of liver could partly result from metabolite of the areca nut [27].

Chronic inflammation of the liver appears to be a risk factor for cirrhosis regardless of the underlying etiology [2830]. Experimental study has indicated persistent hepatocellular damage after chronic feeding with betel quid $[31,32]$. However, the role of betel quid chewing in the development of liver injury and/or cirrhosis, and its interaction with other known risk factors, have not drawn much attention, although Lin et al and Tsai et al independently published case-control studies with cirrhosis and/or chronic liver diseases suspected to be associated with this habit $[22,23]$. In this study we address the independent and interactive roles of habitual betel quid chewing and other known risk factors for biochemical dysfunction and cirrhosis of the liver.

\section{Methods \\ Design}

There are 12 linguistically distinct Aboriginal tribes in Taiwan, which constitutes about $2 \%$ of the total Taiwanese population. They mainly reside in the eastern plains and central mountainous area where is mainly above a height of $500 \mathrm{~m}$. The ethnic status was classified into two groups, "Aboriginal" and "non-Aboriginal". Aboriginal were defined when at least one of the two parents was Atayal Aboriginal. Also, non-Aboriginal were defined when both parents were not Atayal Aboriginal. The non-Aboriginal in this study were mainly Hokkien and Hakka people living in the same community. In this study, we selected the Fushin district in Taoyuan county, which was in the catchment area of our investigations and locates in the northern part of Taiwan with a total of 4,665 residents who were above 20 years of age. Every citizen in the district was invited to participate in a comprehensive physical examination including a detailed questionnaire of health history. A total of 3,010 subjects (64.5\%) responded, which 
included 2,063 Atayal Aboriginal and 947 non-Aboriginal.

This study was first approved by the medical research ethics committee of the hospitals of the Department of Health of Taiwan before commencement, of which the certification number is $900808-03$. The informed consent was provided both orally and in writing, which was conducted under the assistance of local public health nurses who can speak Atayal language.

\section{Data collection and analysis}

After obtaining an informed consent from every subject, 10 c.c. of blood was drawn from every respondent's antecubital vein. All blood samples were centrifuged and serum was frozen down to $-30^{\circ} \sim-70^{\circ} \mathrm{C}$ until they were tested for hepatitis B \& C markers and biochemical function of the liver, including alanine aminotransferase (ALT), aspartate aminotransferase (AST), and gammaglutamyltranspeptidase (GGT).

Test for HBsAg and anti hepatitis C virus (HCV) was conducted by radioimmunoassy with reagents supplied by Abbott company (U.S.A.), and read by clinical Gamma Counter (L.K.B of U.S.A.) with both positive and negative controls. If the reading was on the borderline, the test was repeated 2 3 times. If it consistently showed positive, then the result was considered positive. Liver function tests were performed with reagents supplied by Hitachi 7400. All these serological tests were conducted in the central laboratory of the Taoyuan general Hospital, Department of Health. Every subject was also asked to fill out a questionnaire containing basic demographic information and previous medical history, ethnic group, alcohol drinking, smoking, betel quid chewing, blood transfusion and intravenous injection. Every case was physically examined by a doctor. The history of blood transfusion and intravenous injection was verified from the medical records of the local public health stations, which were the only resource providing health services to the people residing in mountainous area and the data were with a confirmed rate of $99 \%$. Every subject was also invited to receive abdominal ultrasonography examination (Toshiba SAL-38B, Tokyo, Japan).

\section{Dependent variables}

Separate analyses were conducted for biochemical liver function (ALT, AST, GGT) and liver cirrhosis. The dichotomous variables, biochemical liver function, were coded as $\operatorname{ALT}(>=37 ;<37) /$ AST $(>=37 ;<37) /$ GGT $(>=61 /<61)$. Data was separately analyzed for risk factors associated with biochemical liver function/liver cirrhosis. The only one hepatologist conducted all the real time ultrasonography and scored on 10 parameters [33], which ranged from $0,0.5,1$ (mild), 2(moderate), and 3 (marked) for each parameter. The more specific parameters for cirrhosis included nodular liver surface, coarse echotexture, irregular narrowing of hepatic veins and a summed score of more than 4.0 indicated cirrhosis of liver with an accuracy of $95.6 \%$ [33].

\section{Independent variables}

Potential risk factors included ethnic group, gender, age, body mass index (BMI), cigarette smoking, alcohol consumption, betel quid use, $\mathrm{HBsAg}(+)$, and anti-HCV(+). Body mass index (BMI) was calculated $(\mathrm{BMI}=$ weight $/$ height ${ }^{2}, \mathrm{~kg} / \mathrm{m}^{2}$ ). The smoking and drinking behaviors were coded as current smokers/drinkers (continual smoking/drinking least once a week, irrespective of quantity), never smokers/drinkers/(those who never smoked/ drank), or former smokers/drinkers (those who quit smoking/drinking at least one year prior the survey). Betel quid chewing behavior, was coded as betel quid chewers (chewed at least once a week, irrespective of quantity) or never chewers (those who never chewed).

\section{Statistical analyses}

All the information of medical history and laboratory results was collected and put into computer file and processed and analyzed by SAS version no. 6.02. A chi-square test was performed for each univariate analysis first to screen in potentially significant variables. Then, we calculated odds ratio (OR) with 95\% CI of abnormal biochemical function of the liver through multivariate modeling after controlling major risk factors, including age, gender, $\mathrm{BMI}$, ethnic group, alcohol drinking, cigarette smoking, betel quid chewing and hepatitis B \& C status. A backward stepwise procedure was undertaken with a selection of $\mathrm{p}$ value less than 0.001 to be kept in the final model.

\section{Results}

Originally we invited 4,665 residents who were above 20 years of age to take part in the study. Some residents did not participate in the study, because they have already taken jobs in urban area and moved out of the village. In total, we successfully collected blood samples and personal information from 3,010 subjects in this Atayal Aboriginal community of Taiwan. Because our local public health nurses went on door-to-door visits to every household in the community, almost all people who still resided in the community were screened. $48 \%$ of them were males. Table 1 depicted the distribution of risk factors associated with abnormal liver function by using a chi square test in the univariate analysis. The average age was $49.8 \pm 10.2$ years old, with about more than one third of them in the age range of $41 \sim 60$ years old (36.9\%), as summarized on Table 1 . Among these participants, there were 2,063 (68.5\%) Aboriginal, in which about one fifth showed an abnormal ALT, $18.2 \%$ showed an abnormal AST and $28.6 \%$ an abnormal GGT. Aboriginal consist- 
Table I: Frequency of demographic factors and risk factors stratified by ethnicity, and abnormal elevations of biochemical functions (ALT, AST, and GGT) in an Atayal aboriginal community of Taiwan

\begin{tabular}{|c|c|c|c|c|c|}
\hline & \multicolumn{2}{|c|}{ Ethnic groups } & \multirow[b]{2}{*}{$A L T>=37(\%)$} & \multirow[b]{2}{*}{ AST>=37(\%) } & \multirow[b]{2}{*}{ GGT> $>=6 \mathrm{I}(\%)$} \\
\hline & Aboriginal & Nonaboriginal & & & \\
\hline No. of subjects & 2063 & 947 & $496(16.5) *$ & $454(15.1) *$ & $675(22.4) *$ \\
\hline Aboriginal & & & $429(20.8) *$ & $377(18.2) *$ & $591(28.6) *$ \\
\hline \multicolumn{6}{|l|}{ Age(year) } \\
\hline$\leq 20$ & 3 & 1 & $\mathrm{I}(25.0)$ & $0(0)$ & $\mathrm{I}(25.0)$ \\
\hline $21-40$ & $732 *$ & 262 & $191 *(19.2)$ & $194 *(19.5)$ & $240(24.1)$ \\
\hline $41-60$ & 743 & 370 & $211(18.9)$ & $190(17.0)$ & $317 *(28.5)$ \\
\hline$\geq 61$ & 585 & 314 & $93(10.3)$ & $70(7.8)$ & $116(12.9)$ \\
\hline \multicolumn{6}{|l|}{ Gender } \\
\hline Male & 992 & 460 & $357(24.5) *$ & $321(22.1) *$ & $508(34.9) *$ \\
\hline Female & 1071 & 487 & $139(8.9)$ & $133(8.5)$ & $167(10.7)$ \\
\hline Cigarette smoking & $930 *$ & 252 & $248(21.0) *$ & $339(28.7) *$ & $460(38.9) *$ \\
\hline Alcohol drinking & $1226 *$ & 267 & $295(19.8) *$ & $410(27.5) *$ & $577(38.6) *$ \\
\hline Betel quid chewing & $995^{*}$ & 122 & $399(35.7)^{*}$ & $375(33.6)^{*}$ & $290(26.0)$ \\
\hline $\mathrm{HBsAg}(+)$ & 441 & 197 & $153(24.0) *$ & $147(23.1) *$ & $154(24.1) *$ \\
\hline $\overrightarrow{\text { Anti-HCV }}(+)$ & 61 & 25 & $31(36.1) *$ & $33(38.3) *$ & $31(36.1) *$ \\
\hline $\mathrm{BMI}>25$ & $840 *$ & 277 & $384(34.4) *$ & $34 I(30.5)$ & $392(35.1)^{*}$ \\
\hline
\end{tabular}

$*_{p}<0.001$ for crude chi-square test of association between individual risk factors and aboriginal ethnicity

ently showed higher proportions of smoking, alcohol drinking, betel quid chewing, overweight, and abnormal transminases than did non-Aboriginal. In addition, cigarette smokers, alcohol drinkers, HBsAg carriers, people with habitual betel quid chewing, and people who were infected by HCV were found to have significantly higher proportions of abnormal liver transaminases (all $p$ value $<.001$ ). The overall prevalence rates of HBsAg and antiHCV were $21.2 \%$ and $2.9 \%$, respectively.

Table 2 summarizes the results of multiple logistic regression modeling by using a backward stepwise procedure to choose the major risk factors ( $p$ value $<0.001$ ) of abnormal biochemical liver function. After adjustment for gender, BMI, viral hepatitis B and C infections, smoking, alcohol drinking and betel quid chewing, we found that Aboriginal were more likely to develop abnormal elevation of liver transaminases than non-Aboriginal, with an OR of ALT 1.4 (95 \% C.I., 1.2-1.7), AST 1.3 (95 \% C.I., 1.1-2.2), and GGT 1.5 (95 \% C.I., 1.2-2.9). We also found that betel quid chewing was independently associated with abnormal elevation of liver transaminases, with an OR of ALT 1.5 (95 \% C.I., 1.1-1.8) and AST 1.3 (95\% C.I., 1.1-1.7). Current alcohol drinking increased likelihood of developing abnormal elevation of liver transaminases after controlling other risk factors, with 4.7 times of risk for GGT. Similarly, current smoking, male gender, and viral hepatitis B or C infection also showed a significantly increased likelihood of abnormal elevation of ALT, AST, GGT after controlling other risk factors as summarized on Table 2. Increased BMI (> 25) was also associated with increased risks for abnormality in ALT and GGT. There are linear trends for increased severity levels of ALT elevation for both hepatitis virus infection and betel quid chewing, and there was about $4.7 \%(140 / 3010)$ of the study population with more than 5 times of elevation of ALT. After stratification by different levels of elevated ALT, the multiple logistic regression analysis also showed a synergistic effect between viral infection and betel quid chewing, as summarized in Table 3.

Only 1382 subjects came for abdominal ultrasound examination, which detected 41 cases $(3.0 \%)$ with cirrhosis of liver. Among them, 4 cases of liver cancer were subsequently diagnosed and verified with pathology. All 4 cases were male Aboriginal with positive HBsAg and a habit of alcohol drinking, except one quitted about 10 years ago. The average age of subjects with cirrhosis of liver was $46 \pm 14$ years. Approximately $96 \%$ of liver cirrhosis subjects had a history of alcohol drinking (12.5\% of them have already quitted) and $45 \%$ of them showed positive HBsAg. After controlling for other risk factors, we found that Aboriginal were associated with liver cirrhosis, with an adjusted OR of 1.8 (95\% C.I., 1.4-3.2), as shown in Table 4. Similarly, former and current alcohol drinking increased risks of developing cirrhosis of liver with 1.6 and 2.1 times, respectively. Betel quid chewing was independently associated with cirrhosis of liver, with an adjusted OR of 1.7 (95\% C.I., 1.2-2.3). 
Table 2: Frequency, odds ratio(OR) and $95 \% \mathrm{Cl}$ (confidence interval) for different risk factors of abnormal biochemical liver function estimated from multiple regression logistic model after adjustment for age, gender, and education level

\begin{tabular}{|c|c|c|c|c|c|c|}
\hline Variables & ALT & & AST & & GGT & \\
\hline & No. of Cases & & No. of Cases & & No. of Cases & \\
\hline & $>=37 /<37$ OR $(95 \% \mathrm{Cl})$ & & $>=37 /<37$ OR $(95 \% \mathrm{Cl})$ & & $>=6 \mathrm{I} /<6 \mathrm{I}$ OR $(95 \% \mathrm{Cl})$ & \\
\hline \multicolumn{7}{|l|}{ Ethnic group } \\
\hline Non-Aboriginal & $68 / 868$ & 1.0 & $66 / 870$ & 1.0 & $84 / 852$ & 1.0 \\
\hline Aboriginal & $340 / 1724$ & I.4(I.2-I.7) & $429 / 1635$ & $1.3(1.1-2.2)$ & $590 / 1472$ & $1.5(1.2-2.9)$ \\
\hline \multicolumn{7}{|l|}{ Alcohol drinking } \\
\hline Never & $113 / 1402$ & 1.0 & $85 / 1430$ & 1.0 & $97 / 1417$ & 1.0 \\
\hline Former & $16 / 127$ & I.I $(0.6-2.0)$ & $14 / 129$ & $1.0(0.5-1.9)$ & $16 / 129$ & $1.0(0.5-1.9)$ \\
\hline Current & $279 / 1068$ & $1.7(1.2-2.2)$ & $396 / 951$ & $3.1(2.4-4.3)$ & $56|/ 95|$ & $4.7(3.3-6.0)$ \\
\hline \multicolumn{7}{|c|}{ Cigarette smoking } \\
\hline Never & $160 / 1666$ & 1.0 & $156 / 1670$ & 1.0 & $214 / 1612$ & 1.0 \\
\hline Former & $19 / 76$ & I.4(0.8-2.2) & $22 / 73$ & $1.7(1.2-3.1)$ & $27 / 68$ & $1.1(0.6-16)$ \\
\hline Current & $229 / 1068$ & $1.4(1.1-1.8)$ & $317 / 766$ & $1.8(1.3-2.2)$ & $433 / 649$ & $1.6(1.2-2.1)$ \\
\hline \multicolumn{7}{|c|}{ Betel quid chewing } \\
\hline No & $117 / 1584$ & 1.0 & $129 / 1613$ & 1.0 & $154 / 1857$ & 1.0 \\
\hline Yes & $282 / 1117$ & $1.5(1.1-1.8)$ & $246 / 983$ & $1.3(1.1-1.7)$ & $136 / 527$ & $0.7(0.5-1.1)$ \\
\hline \multicolumn{7}{|l|}{ Gender } \\
\hline Female & $117 / 1439$ & 1.0 & $139 / 1417$ & 1.0 & $167 / 1387$ & 1.0 \\
\hline Male & $291 / 1158$ & $1.7(1.5-2.3)$ & $356 / 1093$ & $1.6(1.2-2.0)$ & $507 / 942$ & $2.0(1.9-2.9)$ \\
\hline \multicolumn{7}{|l|}{ BMI } \\
\hline$<=25$ & $214 / 1659$ & 1.0 & $326 / 1547$ & 1.0 & $374 / 1499$ & 1.0 \\
\hline$>25$ & $193 / 929$ & $1.9(1.5-2.4)$ & $167 / 955$ & $1.0(0.7-1.1)$ & $295 / 825$ & $1.9(1.5-2.3)$ \\
\hline \multicolumn{7}{|l|}{$\mathrm{HBV} / \mathrm{HCV}$} \\
\hline$-/-$ & $232 / 971$ & 1.0 & $299 / 1904$ & 1.0 & $470 /|73|$ & 1.0 \\
\hline$+/-$ & $132 / 496$ & I.8(I.4-2.3) & $148 / 480$ & $1.7(1.3-2.2)$ & $148 / 480$ & $0.8(0.6-1.0)$ \\
\hline$-/+$ & $27 / 49$ & $3.7(3.2-9.2)$ & $26 / 50$ & $3.1(2.1-6.2)$ & $25 / 51$ & $2.0(1.3-4.4)$ \\
\hline$+/+$ & $5 / 5$ & $4.2(1.2-17.4)$ & $5 / 5$ & $3.8(1.0-14.1)$ & $6 / 4$ & $2.3(0.7-11.0)$ \\
\hline
\end{tabular}

ALT:Alanine aminotrnsferase; AST:Alanine aminotrnsferase; GGT: $\gamma$-glutamyl transpeptidase; +:positive; -:negative; OR: odds ratio

Table 3: Frequencies and OR (odds ratio) and $95 \% \mathrm{Cl}$ (confidence interval) for betel quid chewing and infection with $\mathrm{HBV} / \mathrm{or} \mathrm{HCV}$ stratified by different severity levels of abnormal alanine transaminase (ALT) estimated from multiple logistic regression model after adjustments for alcohol and cigarette consumptions, age, ethnicity, BMI (body mass index) and gender

\begin{tabular}{|c|c|c|c|c|c|c|c|c|c|}
\hline $\begin{array}{l}\text { Levels of } \\
A L T \\
\text { elevation }\end{array}$ & & $\leq 37\left[\begin{array}{ll}1 & x\end{array}\right]$ & OR (95\%Cl) & $\begin{array}{c}>37-\leq 111 \\
{[1-3 \times]}\end{array}$ & OR $(95 \% \mathrm{Cl})$ & $\begin{array}{c}>111-\leq 185 \\
\quad[3-5 \times]\end{array}$ & OR $(95 \% \mathrm{Cl})$ & $>185[>5 \times]$ & OR $(95 \% \mathrm{Cl})$ \\
\hline $\begin{array}{l}\text { Betel Quid } \\
\text { Chewing }\end{array}$ & $\begin{array}{c}\text { HBV/or } \\
\text { HCV }\end{array}$ & $\begin{array}{l}\text { No. of } \\
\text { subjects }\end{array}$ & & $\begin{array}{l}\text { No. of } \\
\text { subjects }\end{array}$ & & $\begin{array}{l}\text { No. of } \\
\text { subjects }\end{array}$ & & $\begin{array}{l}\text { No. of } \\
\text { subjects }\end{array}$ & \\
\hline \multirow[t]{2}{*}{ No } & - & 1005 & 1.0 & 135 & $0.9(0.6-1.2)$ & 40 & $0.5(0.3-0.8)$ & 23 & $0.3(0.1-0.8)$ \\
\hline & + & 318 & I.3 (I.2-I.5) & 18 & $1.6(1.2-1.9)$ & 21 & $1.8(1.3-2.3)$ & 24 & $2.3(2 . I-2.7)$ \\
\hline \multirow[t]{2}{*}{ Yes } & - & 935 & I.I (0.8-I.5) & 31 & I.3 (I.I-I.3) & 23 & $1.5(1.2-1.9)$ & 28 & $1.7(1.4-2.1)$ \\
\hline & + & 256 & $1.5(1.2-1.8)$ & 36 & $2.3(1.9-2.6)$ & 52 & $3.1(2.5-3.6)$ & 65 & $4.2(3.5-4.7)$ \\
\hline
\end{tabular}

$\mathrm{HBV}: \mathrm{HBsAg}(+)$

$\mathrm{HCV}$ : hepatitis $C$ virus infection

+ : positive

-: negative

OR( $95 \%)$ odds ratio $(95 \% \mathrm{Cl})$

I $x$ : upper normal limit

I-3 $x$ : one to three times of upper normal limit

$5 \times$ : five times of upper normal limit 
Table 4: Adjusted odds ratio(OR) and $95 \% \mathrm{Cl}$ (confidence interval) from multiple logistic regression for risk factors of cirrhosis of liver diagnosed by ultrasonography

\begin{tabular}{lll}
\hline Variables & No. of liver cirrhosis/total & OR $(95 \% \mathrm{Cl})$ \\
\hline $\begin{array}{l}\text { No. of Cases } \\
\text { Ethnic group }\end{array}$ & $4 \mathrm{I} / 1382(3.0 \%)$ & \\
$\quad$ Non-Aboriginal & $7 / 398(1.8 \%)$ & \\
$\quad$ Aboriginal & $34 / 984(3.5 \%)$ & 1.0 \\
Alcohol drinking & & $1.8(1.4-3.6)$ \\
$\quad$ Never & $2 / 681(0.3 \%)$ & \\
Former & $6 / 101(5.9 \%)$ & 1.0 \\
$\quad$ Current & $33 / 600(5.5 \%)$ & $1.6(1.3-4.6)$ \\
Cigarette smoking & & $2.1(1.5-3.5)$ \\
Never & $9 / 892(1.0 \%)$ & \\
Former & $2 / 49(4.1 \%)$ & 1.0 \\
Current & $30 / 441(6.8 \%)$ & $1.3(0.6-10.7)$ \\
Betel quid chewing & & $1.8(1.1-2.7)$ \\
No & $19 / 679(3.5 \%)$ & \\
Yes & $22 / 703(2.2 \%)$ & 1.0 \\
Gender & & $1.7(1.2-2.3)$ \\
Female & $5 / 732(0.7 \%)$ & \\
Male & $36 / 650(5.5 \%)$ & 1.0 \\
BMI & & $1.5(1.2-3.9)$ \\
$<=25$ & $26 / 852(3.1 \%)$ & 1.0 \\
$>25$ & $15 / 530(2.8 \%)$ & $0.9(0.6-1.7)$ \\
HBV/HCV & & 1.0 \\
$-/-$ & $21 / 1020(2.1 \%)$ & $1.9(0.4-12.8)$ \\
$+/-$ & $18 / 300(6.0 \%)$ & $5.4(0.2-7.6)$ \\
$-/+$ & $1 / 32(3.1 \%)$ &
\end{tabular}

+:positive; -:negative OR: odds ratio

\section{Discussion}

Although the frequencies of abnormal ALT, AST, and GGT among Aboriginal were found to be all above $18 \%$ and significantly higher than in non-Aboriginal (all p's < 0.001 ), such associations might not be necessarily causal, especially using a cross-sectional design, requires careful evaluation. In this study, most people in this Aboriginal community were employed by industry related to tourism and sightseeing. It also attracted a lot of non-Aboriginal people to work and reside in the community and provided us an excellent opportunity to compare the findings in these ethnic groups. In fact, the proportions of betel quid chewers among Aboriginals (48.2\%) and non-Aboriginals $(12.8 \%)$ estimated from this study were similar to those reported before $[12,16]$, indicating a relatively representative sample from both ethnic groups. Since the coverage proportions of National Health Insurance for non-Aboriginal and Aboriginal people of this community were about $97 \%$ and $93 \%$, respectively, and both of them were waived from partial co-payment, the likelihood of selection bias seems very low.

After controlling all known risk factors for liver diseases (including viral infections, smoking, alcohol drinking, overweight, gender and ethnicity), there was still $1.3-1.5$ times of increased odds ratio in Aboriginal. Thus, the association deserves our further consideration. There were following possible random errors on measurements of determinants: The history of ethnic group was generally very accurate because only Aboriginals were entitled to a complete waiver for partial co-payment if treated by a doctor. The BMI of every subject was calculated by a nurse immediately after physical measurements of body weight and height. Thus, only the history of alcohol drinking, smoking and betel quid chewing might have a chance to be randomly misclassified, which usually lead toward the null or underestimation.

Except for the unknown factors that might cause non-random errors, our multivariate models controlled for all the known major risk factors, including viral hepatitis B and $\mathrm{C}$, current alcohol drinking and/or cigarette smoking, and increased BMI were found to be independently associated with abnormal elevation of liver transaminase as shown in Tables 2 and 4. Moreover, all these factors except increased BMI were also found to be associated with liver cirrhosis diagnosed through ultrasonography, which further increased the credibility of this study. Therefore, we concluded that biochemical dysfunction of liver may be independently affected by the above risk factors, including betel chewing. Tables 3 and 4 seemed to indicate that persistent elevation of liver transaminases could be an early sign of chronic inflammation that might result in the liver cirrhosis. But we should not make too strong inference because of the limited number of cases and lack of biopsy proof.

Therefore, we concluded that biochemical dysfunction of liver may be independently affected by the above risk factors, including betel chewing. Efforts to reduce the prevalence of liver disease in Aboriginal should, therefore, include efforts to increase quitting of the betel habit.

The above findings deserve to examine possible causal mechanism between betel quid chewing and liver injury. Areca nut was reported to immunologically suppress body defense to HBV/HCV infection [34] and increase the risk of toxic hepatitis[31,32], which might be related to other reactive oxygen adducts formed as a result of habitual betel chewing $[35,36]$. An alternative explanation might be the high proportion (up to $37.5 \%$ ) of betel quids contaminated by aflatoxin [37], which is a well-documented hepatotoxin $[38,39]$. Further studies are needed to determine which components of betel quids may be responsible for liver damage are now required.

Although Safrole, listed as a carcinogen by the Environmental Protection Administration, USA, have been isolated from areca nut [34], the phenolic compounds in betel leaf might be antimutagenic $[40,41]$ or possibly pro- 
tective against carcinogens [42]. Thus, it is difficult to hypothesize. As there were $86 \%$ smokers and $75 \%$ drinkers in Chinese betel chewers [14], the possible mechanisms and interactions among smoking, drinking, and betel chewing deserved further studies on the development of liver cirrhosis.

\section{Conclusion}

The shortened life expectancy in Aboriginal people of Taiwan has long been noticed since the early 1980's [1]. The issue has attracted public concern after democratization of Taiwan. Recently, the government of Taiwan has put a lot of efforts to improve Aboriginal health for the reason of equity and justice. The funding of this study was part of such efforts to determine the major risk factors and prevalence rates of various diseases. The next moves will not only further increase coverage rates of National Health Insurance, improve health manpower and accessibility for healthcare of Aboriginal community in remote area, but also provide programs for reduction in betel chewing rates in Aboriginals to effectively prevent liver diseases

\section{Competing interests}

The authors declare that they have no competing interests.

\section{Authors' contributions}

YC and PH joined in the design of the study. CF and TJ carried out the studies, participated in the sequence alignment and data collection. CF and PH conducted data analysis, and CF drafted the manuscript. JD supervised to complete the data analysis and helped to finalize the manuscript. All of the authors read and approve the manuscript.

\section{Acknowledgements}

This study was supported in part by grants from the National Health Research Institutes (Grant No. NHRI-EX96-9204pp; NHRI-CN-PD96I IP) and from the Department of Health, Executive Yuan, Taiwan.

\section{References}

I. Ko YC, Liu BH, Hsieh SF: Issues on aboriginal health in Taiwan. Kaohsiung J Med Sci 1994, 10:337-351.

2. Zola IK: Pathways to the doctor-from person to patient. Soc Sci Med 1973, 7(9):677-689.

3. Cooper-Patrick L, Crum RM, Ford DE: Characteristics of patients with major depression who received care in general medical and specialty mental health settings. Med Care 1994, 32(I): 15-24.

4. Gilbert GH: Access to and patterns of use of oral health care among elderly veterans. Med Care 1995, 33(I I Suppl):NS78-89.

5. Consensus 1990: Census report of the Republic of China in Taiwan. Department of population. Taipei, Taiwan.

6. Bellwood P: The Austronesian dispersal and the origin of languages. Sci Am 199I, 265:70-75.

7. Strogatz DS: Use of medical care for chest pain: differences between blacks and whites. Am \& Public Health 1990, 80(3):290-294.

8. Chung DC, Ko YC, Chen CJ, Wu CC, Chen ER, Liaw YF, Hwang SJ: Seroepidemiological studies on hepatitis $B$ and $D$ viruses infection among five ethnic groups in southern Taiwan. J Med Virol 1988, 26(4):41 I-4I8.
9. Beasley RP, Hwang LY, Lin CC, Leu ML, Stevens CE, Szmuness W, Chen KP: Incidence of hepatitis B virus infections in preschool children in Taiwan. J Infect Dis 1982, I 46(2): 198-204.

10. Wu JS, Lu CF, Chou WH, Chen HY, Lee HF, Wu YC, Lin SY: High prevalence of hepatitis $C$ virus infection in aborigines in Taiwan. Jpn J Med Sci Biol 1992, 45(4): I65-I74.

II. Hwu HG, Yeh YL, Wang JD, Yeh EK: Alcoholism among Taiwan aborigines defined by the Chinese Diagnostic Interview Schedule: a comparison with alcoholism among Chinese. Acta Psychiatr Scand 1990, 82(5):374-380.

12. Chen WJ, Loh EW, Hsu YP, Cheng AT: Alcohol dehydrogenase and aldehyde dehydrogenase genotypes and alcoholism among Taiwanese aborigines. Biol Psychiatry 1997, $41(6): 703-709$.

13. Norton SA: Betel: consumption and consequences. J Am Acad Dermatol 1998, 38(1):8I-88.

14. Ko YC, Chiang TA, Chang SJ, Hsieh SF: Prevalence of betel quid chewing habit in Taiwan and related sociodemographic factors. J Oral Pathol Med 1992, 2 I (6):261-264.

15. Nelson BS, Heischober B: Betel nut: a common drug used by naturalized citizens from India, Far East Asia, and the South Pacific Islands. Ann Emerg Med 1999, 34(2):238-243.

16. IARC: Betel-quid and areca-nut chewing and some areca-nutderived nitrosamines. Volume 85. IARC Monogr Eval Carcinog Risks Hum; 2004.

17. Ko YC, Huang YL, Lee CH, Chen MJ, Lin LM, Tsai CC: Betel quid chewing, cigarette smoking and alcohol consumption related to oral cancer in Taiwan. Journal of Oral Pathological Medicine 1995, 24( I0):450-453.

18. Lu CT, Yen YY, Ho CS, Ko YC, Tsai CC, Hsieh CC, Lan SJ: A casecontrol study of oral cancer in Changhua County, Taiwan. Journal of Oral Pathological Medicine 1996, 25(5):245-248.

19. Lee KW, Kuo WR, Tsai SM, Wu DC, Wang WM, Fang FM, Chiang FY, Ho KY, Wang LF, Tai CF, et al.: Different impact from betel quid, alcohol and cigarette: risk factors for pharyngeal and laryngeal cancer. International Journal of Cancer 2005, I I 7(5):83 I-836.

20. Yang YH, Lee HY, Tung S, Shieh TY: Epidemiological survey of oral submucous fibrosis and leukoplakia in aborigines of Taiwan. Journal of Oral Pathological Medicine 200I, 30(4):213-219.

2I. Lee CH, Ko YC, Huang HL, Chao YY, Tsai CC, Shieh TY, Lin LM: The precancer risk of betel quid chewing, tobacco use and alcohol consumption in oral leukoplakia and oral submucous fibrosis in southern Taiwan. British Journal of Cancer 2003, 88(3):366-372.

22. Lin HH, Wang LY, Shaw CK, Cheng ML, Chung WK, Chiang HJ, Lin TY, Chen C): Combined effects of chronic hepatitis virus infections and substance-use habits on chronic liver diseases in Taiwanese aborigines. J Formos Med Assoc 2002, I0I(I 2):826-834.

23. Tsai JF, Jeng JE, Chuang LY, Ho MS, Ko YC, Lin ZY, Hsieh MY, Chen SC, Chuang WL, Wang LY, et al.: Habitual betel quid chewing as a risk factor for cirrhosis: a case-control study. Medicine (Baltimore) 2003, 82(5):365-372

24. Tsai JF, Jeng JE, Chuang LY, Ho MS, Ko YC, Lin ZY, Hsieh MY, Chen SC, Chuang WL, Wang LY, et al.: Habitual betel quid chewing and risk for hepatocellular carcinoma complicating cirrhosis. Medicine (Baltimore) 2004, 83(3): 176- 187.

25. Tung TH, Chiu YH, Chen LS, Wu HM, Boucher BJ, Chen TH: A population-based study of the association between areca nut chewing and type 2 diabetes mellitus in men (Keelung Community-based Integrated Screening programme No. 2). Diabetologia 2004, 47( I 0): I776-I78I.

26. Yang MJ, Chung TC, Hsu TY, Ko YC: Betel quid chewing and risk of adverse birth outcomes among aborigines in eastern Taiwan. J Toxicol Environ Health A 200I, 64(6):465-472.

27. Nair J, Ohshima H, Friesen M, Croisy A, Bhide SV, Bartsch H: Tobacco-specific and betel nut-specific $\mathbf{N}$-nitroso compounds: occurrence in saliva and urine of betel quid chewers and formation in vitro by nitrosation of betel quid. Carcinogenesis 1985, 6(2):295-303.

28. Caldwell SH, Oelsner DH, lezzoni JC, Hespenheide EE, Battle EH, Driscoll CJ: Cryptogenic cirrhosis: clinical characterization and risk factors for underlying disease. Hepatology 1999 , 29(3):664-669.

29. Corrao G, Torchio P, Zambon A, D'Amicis A, Lepore AR, di Orio F: Alcohol consumption and micronutrient intake as risk fac- 
tors for liver cirrhosis: a case-control study. The Provincial Group for the study of Chronic Liver Disease. Ann Epidemiol 1998, 8(3): 154-159.

30. Du CL, Wang JD: Increased morbidity odds ratio of primary liver cancer and cirrhosis of the liver among vinyl chloride monomer workers. Occup Environ Med 1998, 55(8):528-532.

31. Sarma AB, Chakrabarti J, Chakrabarti A, Banerjee TS, Roy D, Mukherjee $D$, Mukherjee $A$ : Evaluation of pan masala for toxic effects on liver and other organs. Food Chem Toxicol 1992, 30(2): $161-163$.

32. Singh $A$, Rao AR: Evaluation of the modifying influence of arecanut on the garlic-modulated hepatic detoxication system enzymes, sulfhydryl content, and lipid peroxidation in mice. Teratog Carcinog Mutagen 1995, I 5(3): I 27-I 34.

33. Yang PM, Huang GT, Lin JT, Sheu JC, Lai MY, Su IJ, Hsu HC, Chen DS, Wang TH, Sung JL: Ultrasonography in the diagnosis of benign diffuse parenchymal liver diseases: a prospective study. J Formos Med Assor 1988, 87(10):966-977.

34. Shahabuddin S, Rao AR, Mustafa AS: Effect of arecoline on the humoral \& cell mediated immune responses in mice. Indian J Exp Biol 1980, I 8(12):1493-1494.

35. Houglum K, Filip M, Witztum JL, Chojkier M: Malondialdehyde and 4-hydroxynonenal protein adducts in plasma and liver of rats with iron overload. J Clin Invest 1990, 86(6): 1991-1998.

36. Tsukamoto $\mathrm{H}$ : Oxidative stress, antioxidants, and alcoholic liver fibrogenesis. Alcohol 1993, 10(6):465-467.

37. Raisuddin S, Misra JK: Aflatoxin in betel nut and its control by use of food preservatives. Food Addit Contam 1991, 8(6):707-712

38. Bhat RV: Aflatoxin and liver injury. Trop Gastroenterol 1996 17(3): 153-160.

39. Krishnamachari KA, Bhat RV, Nagarajan V, Tilak TB: Hepatitis due to aflatoxicosis. An outbreak in Western India. Lancet 1975, I(79|5): I06I-1063.

40. Amonkar AJ, Nagabhushan M, D'Souza AV, Bhide SV: Hydroxychavicol: a new phenolic antimutagen from betel leaf. Food Chem Toxicol 1986, 24( ( 2): | 32 I-I324.

4I. Padma PR, Amonkar A], Bhide SV: Antimutagenic effects of betel leaf extract against the mutagenicity of two tobacco-specific N-nitrosamines. Mutagenesis 1989, 4(2): 154-156.

42. Padma PR, Lalitha VS, Amonkar AJ, Bhide SV: Anticarcinogenic effect of betel leaf extract against tobacco carcinogens. Cancer Lett 1989, 45(3): 195-202.

\section{Pre-publication history}

The pre-publication history for this paper can be accessed here:

http://www.biomedcentral.com/1471-230X/8/13/pre

pub
Publish with Biomed Central and every scientist can read your work free of charge

"BioMed Central will be the most significant development for disseminating the results of biomedical research in our lifetime. "

Sir Paul Nurse, Cancer Research UK

Your research papers will be:

- available free of charge to the entire biomedical community

- peer reviewed and published immediately upon acceptance

- cited in PubMed and archived on PubMed Central

- yours - you keep the copyright
BioMedcentral 